\title{
Rekreasyon ve Rekreasyon Yönetimi Lisans Programlarının Kontenjanlarının Değerlendirilmesi
}

Özkan TÜTÜNCÜ

Prof. Dr., Dokuz Eylül Üniversitesi, Necat Hepkon Spor Bilimleri Fakültesi

\section{Giriş}

Anatolia: Turizm Araştırmaları Dergisi turizm, rekreasyon ve boş zaman çalışmaları üzerine bugüne kadar birçok makale yayınlandı ve yayınlamaya devam etmektedir. Derginin adı 'Turizm Araştırmaları' olmakla birlikte, dergi disiplinlerarası ve çok disiplinli çalışmaları kuruluşundan beri desteklemekte ve yayıncılığını bu kapsamda sürdürmektedir. Ülkemizde ve dünyada hem turizm hem de rekreasyon alanında yapilan araştırmaların ilgi odaklarından biri de eğitim bilimleridir. Bu kapsamda rekreasyon incelemeleri köşesinde, rekreasyon ve boş zaman ile ilgili birçok alanda makale yazmakla beraber, özellikle rekreasyon eğitimi ile ilgili çalışmalara yer vermekteyiz.

Kisa bir değerlendirme ile rekreasyon lisans programlarının geçmişine baktığımızda, ülkemizde rekreasyon (rekreasyona) yönelik lisans programlarının öncelikle Beden Eğitimi ve Spor Yüksekokulları (BESYO) ve akabinde Spor Bilimleri Fakültelerinde (SBF) dört yıllık eğitimlerine başladığını, daha sonrasında Turizm İşletmeciliği ve Otelcilik Yüksekokullarının (TIOYO) Turizm Fakültelerine (TF) dönüşmesiyle, bu okullarda da rekreasyon yönetimi programlarının hızla açılmaya başladığını görmekteyiz. Tüm bu gelişmeler rekreasyona yönelik lisans eğitim programları üzerine yeni değerlendirmeler ve çalışmalar yapılmasını beraberinde getirmektedir.

Anatolia: Turizm Araştırmaları Dergisi ve Turizm Akademisi bünyesinde rekreasyon eğitimi ile ilgili yapılan çalışmalara bakıldığında; rekreasyon ve rekreasyon yönetimi programlarının amaçlarının (Kozak, Tütüncü ve Kozak 2014), rekreasyon yönetimine yönelik üniversite düzeyinde müfredat geliştirme önerilerinin (Tütüncü 2008), rekreasyona yönelik disiplinler arası doktora programlarının (Tütüncü 2012), fakülteleşme ve rekreasyon bölümlerinin (Tütüncü 2018) ve rekreasyon yönetimi ve turizm işletmeciliği bölüm müfredatlarının karşılaştırılmasının (Tütüncü, Akgündüz ve Yeşilyurt 2019) ele alındığ 1 görülmektedir. Yapılan değerlendirme ve çalışmaların daha ziyade müfredatlar üzerinde yoğunlaştığı belirtilebilir. Müfredatlar ile ilgili çalışmaların her zaman gündemde olması, değişen şartlara bağlı olarak eğitim sisteminin de güncellenme gereksiniminden dolayı gayet doğaldır. Öte yandan 2021 yılında Öğrenci Seçme ve Yerleştirme Merkezi (ÖSYM) tarafından gerçekleştirilen yükseköğretim kurumları sınavının ortaya koyduğu sonuçlara bağlı olarak, dikkat çeken bazı gelişmeler bulunmaktadır. Bu kapsamda çalışmanın amacı rekreasyon ve rekreasyon yönetimi programlarının kontenjanları, yerleşen öğrenci sayıları ve doluluk yüzdeleri üzerinden durum tespiti yapmaktır.

\section{ÇALIŞMANIN YÖNTEMI}

2021 yılında Yükseköğretim Kurulunun (YÖK) gerçekleştirdiği ÖSYM sınavına göre, rekreasyon ve rekreasyon yönetimi lisans programlarının kontenjanları ve bu kontenjanların dolulukları, kabul edilen ve yerleştirilen öğrenci sayıları sanal ortamda yayınlanmıştır (ÖSYM 2021). Çalışmanın kapsamı sadece ÖSYM puanına göre yerleştirme yapan lisans programlarını içine al- 
maktadır. Diğer bir ifade ile özel yetenek sınavı ile öğrenci kabul eden BESYO ve SBF lisans programları kapsam dışında tutulmuştur. Bunun nedeni özel yetenek sınavı ile öğrenci kabul eden rekreasyon lisans programlarının an itibarıyla kontenjanlarının ne kadar dolu olduğunun saptanamamış ve YÖK tarafından ilan edilmemiş olmasıdır. Bu çerçevede çalışma ikincil veriler üzerinden, rekreasyon ve rekreasyon yönetimi programlarının nasıl farklılaştı̆̆ını belirlemeye odaklanmaktadır. Bu değerlendirmeler 2021 yılı yükseköğretim kurumları sınavının ilk yerleştirmeleri üzerinden yapılmaktadır. Bunun nedeni ise ilk tercih olarak yerleşen öğrencilerin, diğer öğrencilere göre alan belirlemesini daha sağlıklı yapma olasılığ 1 ve çalışmanın yapıldığ 1 an itibarryla henüz diğer ek yerleştirmelerin sonuçland1rılmamış olmasıdır.

\section{IKINCIL VERILER VE DEĞERLENDIRILMESi}

ÖSYM'nin 2021 yılında gerçekleştirmiş olduğu yükseköğretim kurumları sınav sonuçlarının yayınlanmasına bağlı olarak ikincil verilerin değerlendirilmesi mümkün olmuştur. Bununla birlikte burada çıarımsal değil, sadece bu yılın verileri üzerinden tanımlayıcı ve durum saptayıcı bir değerlendirme yapılması hedeflendiğinden, öncelikle rekreasyon ve rekreasyon yönetimi programlarının kendi içinde devlet ve vakıf üniversiteleri bazında; örgün, ikinci öğretim ve açı öğretim programları kapsamında, daha sonra da karşılaştırmalı olarak ele alınması uygun görülmüştür. SBF'lerdeki kamuya ait rekreasyon lisans programlarına ilişkin veriler Tablo 1'de verilmektedir.

Tablo 1 incelendiğinde öncelikle devlet üniversitelerindeki rekreasyon lisans programlarının tümünün SBF bünyesinde olduğu görülmektedir. Diğer bir ifade ile bu programlar yüksekokullarda değil fakültelerin içinde yer almaktadır. Özel yetenekle değil ÖSYM sınavı ile öğrenci kabul eden toplamda 13 rekreasyon programı bulunmaktadır. Eşit ağırlıklı puan (EA) ile öğrenci alan bu programlardan sadece bir tanesi (Gazi Üniversitesi, SBF, Rekreasyon Program1), 62 kişilik kontenjanının hepsini ilk yerleştirmede doldurmuştur. Ülkemizin en köklü rekreasyon lisans programına sahip bu kurumunun, böyle bir sonuç elde etmiş olması şaşırtıcı değildir. Ardından gelen Kocaeli Üniversitesi, SBF, Rekreasyon Programı 52 kişilik kontenjanın 37'sini doldurmuştur. İlk tercihlere göre kontenjanının $0,29^{\prime}$ u boşta kalmıştır. En iyi üçüncü program ise Eskişehir Teknik Üniversitesi, SBF bünyesindedir. 52 kişilik kontenjanının 0,63'ünü doldurmuş, 0,37'lik kontenjanı ilk tercihlerde boşta kalmıştır. 13 rekreasyon lisans programindan sadece üç tanesi kontenjanlarının 0,50'sinden fazlasını doldurabilmiş, geri kalan 10 program ise tercihlerde istenilen düzeylere ulaşamamıştır. Bu 10 programdan ikisi kontenjanlarına hiçbir öğrenciyi yerleştiremezken, üç tanesi sadece birer öğrenci tercihi ile karşı karşıya kalmışlardır. Toplamda SBF'ler bünyesinde yer alan 600 kişilik kontenjanın, 188 öğrenci tarafından tercih edilmesi, kontenjanların 0,69'unun boş kaldığı sonucunu ortaya çıarmaktadır. 0,31'lik doluluğu ilk dörtte yer alan üniversitelerin yönlendirdiği görülmektedir. SBF bünyesinde ikinci öğretim olarak yer alan rekreasyon lisans programlarına ilişkin veriler Tablo 2'de verilmektedir.

Tablo 2 incelendiğinde öncelikle devlet üniversitelerindeki rekreasyon ikinci öğretim lisans programlarının tümünün SBF bünyesinde olduğu görülmektedir. Diğer bir ifade ile bu programlar da yüksekokullarda değil, fakültelerin içinde yer almaktadır. ÖSYM sınavı ile öğrenci yerleştiren

Şekil 1. Öğrencilerin Devmet Üniversiteleri Rekreasyon Örgün Eğitim Programları tercihleri (2021)

\begin{tabular}{|lrrrr|}
\hline \hline Üniversite-Fakülte & Puan & Kontenjan & Yerleşen & Doluluk \\
\hline Atatürk Üniversitesi, SBF & EA & 52 & 7 & 0,13 \\
\hline Bartın Üniversitesi, SBF & EA & 52 & 1 & 0,02 \\
\hline Bingöl Üniversitesi, SBF & EA & 52 & 1 & 0,02 \\
\hline Eskişehir Teknik Üniversitesi, SBF & EA & 52 & 33 & 0,63 \\
\hline Gazi Üniversitesi, SBF & EA & 62 & 62 & 1,00 \\
\hline Kocaeli Üniversitesi, SBF & EA & 52 & 37 & 0,71 \\
\hline Munzur Üniversitesi, SBF & EA & 41 & 0 & 0,00 \\
\hline Muş Alparslan Üniversitesi, SBF & EA & 41 & 1 & 0,02 \\
\hline Ondokuz Mayıı Üniversitesi, SBF & EA & 41 & 18 & 0,44 \\
\hline Sakarya Uygulamalı Bilimler Üniversitesi, SBF & EA & 52 & 13 & 0,25 \\
\hline Trabzon Üniversitesi, SBF & EA & 31 & 3 & 0,10 \\
\hline Uşak Üniversitesi, SBF & EA & 31 & 0 & 0,00 \\
\hline Yalova Üniversitesi, SBF & EA & 41 & 12 & 0,29 \\
\hline Toplam & & 600 & 188 & 0,31 \\
\hline
\end{tabular}


Tablo 2. Öğrencilerin Devlet Üniversiteleri Rekreasyon İkinci Öğretim Programları Tercihleri (2021)

\begin{tabular}{|lrrrr|}
\hline \hline Üniversite-Fakülte-Bölüm & Puan & Kontenjan & Yerleșen & Doluluk \\
\hline Atatürk Üniversitesi, SBF & EA & 41 & 0 & 0,00 \\
Bartın Üniversitesi, SBF & EA & 41 & 0 & 0,00 \\
Kocaeli Üniversitesi, SBF & EA & 41 & 1 & 0,02 \\
\hline Toplam & & 123 & 1 & 0,01 \\
\hline
\end{tabular}

toplamda üç rekreasyon ikinci öğretim programı bulunmaktadır. Eşit ağırlıklı puan ile öğrenci alan bu programlardan en iyisi 41 kişilik kontenjanından sadece bir tanesini doldurabilmiştir. Diğer iki program ise kontenjanlarına hiçbir öğrenciyi yerleştirememiştir. Toplamda SBF'ler bünyesinde yer alan ikinci öğretim programlarının 123 kişilik kontenjanın, bir öğrenci tarafından tercih edilmesi, kontenjanların 0,99'unun boş kaldığ1 sonucunu ortaya koymaktadır. Üniversitelerde açık öğretim üzerinden eğitim veren rekreasyon lisans programlarına ilişkin veriler Tablo 3'te verilmektedir.

Tablo 3 incelendiğinde ÖSYM sınavı ile öğrenci yerleştiren toplamda iki rekreasyon açık öğretim programı bulunmaktadır. Eşit ağırlıklı puan ile öğrenci kabul eden bu programlardan Atatürk Üniversitesi 205 kişilik kontenjanının 19 tanesini doldurabilmiştir. İlk tercihlere göre toplam kontenjanının 0,91'i boşta kalmıştır. Diğger programı bünyesinde bulunduran İstanbul Üniversitesi ise 154 kişilik kontenjanından 27 tanesini doldurabilmiştir. İlk tercihlere göre toplam kontenjanının 0,18 'i tercih edilmiştir. Açık öğretim rekreasyon programlarında toplamda 359 kişilik kontenjan var iken, bunların sadece 46'sı doldurulabilmiştir. Diğer bir ifade ile toplam açık öğretim kontenjanlarının 0,13'ü değerlendirilebilmiştir. Vakıf üniversitelerinde eğitim veren rekreasyon lisans programlarına ilişkin veriler Tablo 4'te verilmektedir.

Tablo 3. Öğrencilerin Rekreasyon Açı Öğretim Programları Tercihleri (2021)

\begin{tabular}{|lrrrr|}
\hline Üniversite-Fakülte-Bölüm & Puan & Kontenjan & Yerleșen & Doluluk \\
\hline Atatürk Üniversitesi, AÖF & EA & 205 & 19 & 0,09 \\
istanbul Üniversitesi, AUEF & EA & 154 & 27 & 0,18 \\
\hline Toplam & & 359 & 46 & 0,13 \\
\hline \hline
\end{tabular}

Tablo 4. Öğrencilerin Vakıf Üniversiteleri ve KKTC'deki Rekreasyon Örgün Eğitim Programları Tercihleri (2021)

\begin{tabular}{|lrrrr|}
\hline \hline Üniversite Adı & Puan & Kontenjan & Yerleşen & Doluluk \\
\hline Lokman Hekim Üniversitesi (Ankara), SBF & EA & 20 & 3 & 0,15 \\
Kıbrıs Sağlık Ve Toplum Bilimleri & & & & \\
Üniversitesi, BESYO & EA & 10 & 0 & 0,00 \\
Uluslararası Kıbrıs Üniversitesi, BESYO & EA & 10 & 0 & 0,00 \\
Yakın Doğu Üniversitesi, SBF & EA & 12 & 0 & 0,00 \\
Doğu Akdeniz Üniversitesi, TOYO & EA & 3 & 0 & 0,00 \\
\hline Toplam & & 55 & 3 & 0,05 \\
\hline \hline
\end{tabular}

Tablo 4 incelendiğinde vakıf üniversitelerindeki rekreasyon lisans programlarının karma bir şekilde SBF, BESYO ve Turizm ve Otelcilik Yüksek Okulları'nda (TOYO) yer aldığı görülmektedir. Toplamda beş farklı rekreasyon programı bulunmaktadır. Bunlardan biri Türkiye'de diğerleri ise Kuzey Kıbrıs Türk Cumhuriyeti'nde (KKTC) yer almaktadır. KKTC'deki programlar turizm ve spor alanındaki yüksekokullarda aynı adla, isim

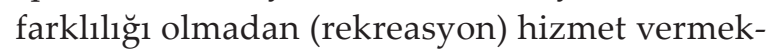
tedir. Eşit ağırlıklı puan ile öğrenci alan bu programlardan sadece Türkiye'deki Lokman Hekim Üniversitesi rekreasyon programının 20 kişilik kontenjanına üç öğrenci kabul edebilmiştir. Diğerleri ise kontenjanlarına bir öğrenci dahi kabul edememiştir. Vakıf ve KKTC'deki üniversitelerde toplamda 55 kişilik kontenjanın, üç öğrenci tarafından tercih edilmesi, kontenjanların 0,95'inin boş kaldığı sonucunu ortaya koymaktadır.

Sadece ÖSYM sınavına bağlı olarak öğrenci kabul eden devlet ve vakıf üniversiteleri bünyesindeki $22 \mathrm{SBF}$ ve BESYO rekreasyon program1nın (açık öğretimler dahil) 2021 yılı için toplam kontenjanı 1.134 kişidir (KKTC'deki TOYO bünyesindeki rekreasyon programı hariç tutulmuştur). Kontenjanların 238 kişilik kısmı öğrenciler tarafından tercih edilmiş, toplamda 896 kişilik kontenjan boşta kalmıştır. Spor bilimleri alanında hizmet veren rekreasyon lisans programlarının 2021 yılındaki ilk yerleştirme doluluk oranı 0,21'dir.

SBF ve BESYO'lardaki rekreasyon programlarının mevcut durumu net olarak değerlendirilmeden, bu okullarda yeni programlar açılmış ve açılmaya devam etmektedir. Bunlara ek olarak 
Turizm Fakülteleri aynı kervana katılmış, fakültelerdeki mevcut programlara ek olarak rekreasyon yönetimi programları oluşturulmuştur. Turizm ile ilgili lisans eğitimi veren devlet ait okullardaki örgün rekreasyon yönetimi programlarına ilişkin 2021 yılında öğrencilerin yapmış oldukları tercihler ve buna ilişkin veriler Tablo 5 'te verilmektedir.

Tablo-5 incelendiğinde öncelikle devlet üniversitelerindeki rekreasyon lisans programlarının hem TF'lerde hem de yüksekokullarda yer aldığ görülmektedir. Programların büyük çoğunluğu fakültelerin bünyesindedir. Fakültelerde 14, yüksekokullarda beş adet olmak üzere toplamda 19 adet rekreasyon yönetimi programı bulunmaktadır. Sözel ağırlıklı puan (SÖZ) ile öğrenci alan bu programlardan yedi tanesi kontenjanlarının hepsini ilk yerleştirmede doldurmuştur. Bunların tamamı fakülteler bünyesinde yer almaktadır. Fakültelerden sadece dört tanesi kontenjanlarının 0,50'sini doldurabilmiştir. Bunlardan en düşük olanı Giresun Üniversitesi, TF rekreasyon yönetimi programının 31 kişilik kontenjanını, sadece

Tablo 5. Öğrencilerin Devlete Ait Rekreasyon Yönetimi Örgün Eğitim Programları Tercihleri (2021)

\begin{tabular}{|c|c|c|c|c|}
\hline Üniversite Adı & Puan & Kontenjan & Yerleşen & Doluluk \\
\hline Akdeniz Üniversitesi, Manavgat, TF & söz & 52 & 52 & 1,00 \\
\hline Akdeniz Üniversitesi, TF & söz & 52 & 52 & 1,00 \\
\hline Balıkesir Üniversitesi, TF & söz & 41 & 41 & 1,00 \\
\hline Hacı Bayram Veli Üniversitesi, TF & söz & 89 & 89 & 1,00 \\
\hline Karabük Üniversitesi, TF & söz & 41 & 14 & 0,34 \\
\hline Kırklareli Üniversitesi, TF & söz & 36 & 33 & 0,92 \\
\hline Mersin Üniversitesi, TF & söz & 41 & 41 & 1,00 \\
\hline Necmettin Erbakan Üniversitesi, TF & söz & 62 & 57 & 0,92 \\
\hline Sakarya Uygulamalı Bilimler Üniversitesi, TF & söz & 41 & 41 & 1,00 \\
\hline Selçuk Üniversitesi, TF & söz & 31 & 31 & 1,00 \\
\hline Yüzüncü Yıl Üniversitesi, TF & söz & 41 & 19 & 0,46 \\
\hline Giresun Üniversitesi, TF & söz & 31 & 6 & 0,19 \\
\hline Dumlupınar Üniversitesi, UBF & söz & 31 & 21 & 0,68 \\
\hline Korkut Ata Üniversitesi, UBF & söz & 41 & 10 & 0,24 \\
\hline Ara Toplam & & 630 & 507 & 0,80 \\
\hline Karamanoğlu Mehmetbey Üniversitesi, UBYO & söz & 41 & 6 & 0,15 \\
\hline Gaziosmanpaşa Üniversitesi, TioYO & söz & 41 & 1 & 0,02 \\
\hline Siirt Üniversitesi, TiOYO & söz & 41 & 10 & 0,24 \\
\hline Sinop Üniversitesi, TiOYO & söz & 41 & 25 & 0,61 \\
\hline Harran Üniversitesi, TOIYO & söz & 41 & 15 & 0,37 \\
\hline Ara Toplam & & 205 & 57 & 0,28 \\
\hline Genel Toplam & & 835 & 564 & 0,68 \\
\hline
\end{tabular}

altı kişi tercih etmiş, doluluğu 0,19 düzeyinde kalmıştır. Fakültelerin 630 kişilik kontenjanının, 507 öğrenci tarafından tercih edildiği, doluluklarının 2021 yılında ilk tercihlerde 0,80 olduğu görülmektedir. Öte yandan yüksekokullar bünyesinde yer alan rekreasyon yönetimi programlarının durumu, fakültelerdeki programlar kadar iyi değildir. Yüksekokullardan sadece bir tanesi 41 kişilik kontenjanının 0,61'ini 25 öğrenci ile doldurmuştur. Gaziosmanpaşa Üniversitesi rekreasyon yönetimi programının 41 kişilik kontenjanı olmasına rağmen, bu programı sadece bir kişi tercih etmiştir. Karamanoğlu Mehmetbey Üniversitesi'nin ilgili programı aynı kontenjana sahip olup, sadece altı kişi tarafından tercih edilmiştir. Yüksekokullara ait toplam 205 kişilik kontenjanın, 57'si öğrenciler tarafından rağbet görmüş, doluluk oranı 0,28 'de kalmıştır. Turizm alanında faaliyet gösteren devlete ait örgün rekreasyon yönetimi programlarının toplam kontenjanı 835 olup, bunların 564'üne öğrenci kabul edilmiş ve doluluk oranı 0,68 olmuştur. Turizm ile ilgili lisans eğitimi veren okullardaki ikinci eğitim rekreasyon yönetimi programlarına ilişkin 2021 yılında öğrencilerin yapmış oldukları tercihler ve buna ilişkin veriler Tablo 6'da verilmektedir.

Tablo-6 incelendiğinde devlet üniversitelerindeki rekreasyon yönetimi ikinci öğretim lisans programı bir tane olup, TF bünyesinde olduğu görülmektedir. Necmettin Erbakan Üniversitesi 41 kişilik kontenjanından sadece dört tanesini doldurabilmiştir. İkinci öğretim kontenjanının 0,90'ının boş kaldığı sonucu ortaya çıkmaktadır.

Devlet üniversiteleri bünyesindeki örgün ve ikinci öğretim rekreasyon yönetimi programlarının 2021 yılı için toplam kontenjanı 879 kişidir (KKTC'deki TOYO bünyesindeki rekreasyon programı dahil edilmiştir). Kontenjanların 568 kişilik kısmı öğrenciler tarafından tercih edilmiş, toplamda 311 kişilik kontenjan boşta kalmıştır. Turizm alanında hizmet veren tüm rekreasyon

Tablo 6. Öğrencilerin Devlet Üniversiteleri Rekreasyon Yönetimi İkinci Öğretim Programları Tercihleri (2021)

\begin{tabular}{|lrrrr|}
\hline \hline Universite Adı & Puan & Kontenjan & Yerleşen & Doluluk \\
\hline Vecmettin Erbakan Üniversitesi, TF & SÖz & 41 & 4 & 0,10 \\
\hline
\end{tabular}


yönetimi lisans programlarının 2021 yılındaki ilk yerleştirme doluluk oranı 0,65'tir.

\section{TARTIŞMA VE SONUÇ}

Her ne kadar öğrenci kaynakları ve müfredatları bakımından farklılık gösteren iki program olsa da sonuç olarak rekreasyon alanında istihdam edilebilecek potansiyel rekreasyon uzmanlar1nı yetiştiren rekreasyon ve rekreasyon yönetimi programlarının kontenjanları ve tercih edilme oranlarında, önemli farklılıklar bulunmaktadır. 2021 yılında yapılan ÖSYM sınavında öğrencilerin yaptıkları ilk tercihlere göre örgün rekreasyon lisans programları 0,31'lik, rekreasyon yönetimi programları ise 0.68 lik kontenjanların doldurabilmişlerdir. Rekreasyon yönetimi programları, rekreasyon programlarına göre daha fazla talep görmüştür. Bunun en büyük nedenlerinden biri TF ve turizm ile ilgili yüksek okullardaki rekreasyon yönetimi programlarının öğrencilerini sözel puanla kabul etmeleri olabilir.

Yerleştirme oranı düşük olan ve ÖSYM puanı ile öğrenci kabul eden SBF ve BESYO'lardaki rekreasyon lisans programları, TF'lerindeki rekreasyon yönetimi programlarının daha yüksek doluluk oranına sahip olmasının sözel puan ile öğrenci almalarından kaynaklanabileceğini düşünerek, öğrenci yerleştirme düzeylerini yukarıya çekmek için özel yetenek sınavına bağlı öğrenci almaya yönelebilirler. Bununla birlikte bu tür bir yaklaşım, sadece kontenjanların doldurulması için yapılacak ise çok sağlıklı olmayacaktır. Önemli olan sadece lisans programlarının doluluklarını artırmak değil, eğitim programlarının içini doldurmak ve mezunlarının iş bulabileceği sağlıklı bir sistemi oluşturabilmektir.

2021 yilında örgün rekreasyon yönetimi programlarına ilk tercihlerde bir öğrenci yerleştiren bir devlet okulu, örgün rekreasyon programlarında ise bir kişi ve altı (sıfır) öğrenci yerleştiren beş devlet okulu ve ikinci öğretim rekreasyon programlarına bir kişi ve altı öğrenci yerleştiren üç devlet okulu bulunmaktadır. Öncelikle ikinci eğitim rekreasyon programlarının, şartlar olgunlaşıncaya kadar kapatılması önerilebilir. Buna ek olarak açık öğretim rekreasyon programlarının kabul ettiği öğrenci sayıları, bir sınıfı doldurabi- lecek yeter sayıya dahi neredeyse ulaşamamaktadır. Ekonomide kaynakların sınırlı olmasından ve bu kaynakların daha verimli kullanılması elzem olduğundan, en azından şu şartlar altında ikinci öğretim ve açık öğretimde yer alan rekreasyon lisans programlarının kapatılması, örgün eğitim programlarının desteklenmesi adına da önerilebilir.

Köklü üniversitelerde ve büyük şehirlerde yer alan rekreasyon ve rekreasyon yönetimi programlarının daha fazla öğrenciyi cezbettiği görülmektedir. Bu kapsamda açlacak olan programların, kuruluş yerini de dikkate almasında fayda bulunmaktadır. Var olan durum iyi analiz edilmeli, rekreasyon ve rekreasyon yönetimi programlarının geleceği bir planlama dahilinde yürütülmelidir. Yeni açılan okullarda hem rekreasyon hem de rekreasyon yönetimi kontenjanlarının, büyükşehirler hariç, 30 kişi ile sınırlandırılması, rekreasyon yönetimi bölümlerinin sadece fakültelerde açılması ve yüksekokullarda bu bölümlerin olgunlaşacak kadrolarını ve eğitim-öğretim altyapılarını oluşturuncaya kadar program açmaması, yine kaynaklarımızın daha doğru kullanılması adına önerilebilir.

Şu an için rekreasyon yönetimi programlarının doluluk oranları, ilgili fakülteleri sevindirebilir ama geleceğe yönelik sorunların giderilememesi, daha farklı sorunlara neden olabilecektir. TF'lerindeki rekreasyon yönetimi bölümlerine yönelik bu talep, plansız bir şekilde yeni bölümlerin açılmasını teşvik edebilir. Önemli olan program sayılarının ve kontenjanlarının artırılması değildir. En iyi örnek SBF bünyesindeki rekreasyon programlarıdır. Açık öğretim ve ikinci öğretim programları karşılaştırmaya dahil edilmese dahi, rekreasyon programlarının şu an ki doluluk oranları 0,31'dir. Bölümler birçok nedenle ve değişik baskılarla programların kontenjanlarını artırmak durumunda kalmaktadır. Görülen o ki kontenjanların artması, diğer bir ifade ile arzın artması, her zaman talebi artırmamaktadır. Öte yandan vakıf üniversitelerindeki ve KKTC'deki kontenjanlar incelendiğinde, program başına en fazla 20 ve hatta çoğunluğunda 10 öğrenci olduğu görülmektedir. Aslında bu kontenjanların düşük olduğu dahi söylenebilir. Bununla birlikte ne 
yazık ki toplam kontenjanlarının 0,05'ini doldurabilmişlerdir. Diğer bir ifade ile bu programlar öğrencilere cazip gelmemektedir.

Alana yönelik mesleki tanımların yasal olarak düzenlenmemiş olması, mezunların istihdamını kısıtlayıcı bir etmendir. Bu gibi yapısal sorunlar, rekreasyon programların tercih edebilecek potansiyel öğrencileri, farklı alanları seçmeye zorlayabilmektedir. Ülkemizde içinde tamamen rekreasyon alanında araştırma yapmış, disiplinler arası yaklaşıma sahip öğretim üyelerinin bulunduğu bir rekreasyon veya rekreasyon yönetimi bölümü bulmak çok kolay değildir. Tüm bunlar alanın geleceği hakkında bazı soruların oluşmasına neden olmakta ve programların tavsiye edilmesini de olumsuz yönde etkilemektedir.

\section{KISALTMALAR}

AÖF = Açı Öğretim Fakültesi

AUÖF = Açık ve Uzaktan Eğitim Fakültesi

$\mathrm{BESYO}=$ Beden Eğitimi ve Spor Yüksekokulu

$\mathrm{EA}=$ Eşit Ağırlıklı

$\mathrm{SBF}=$ Spor Bilimleri Fakültesi

SÖZ = Sözel Ağırlıklı

$\mathrm{TF}=$ Turizm Fakültesi

TİOYO = Turizm İşletmeciliği ve Otelcilik Yüksekokulu
TOİYO = Turizm ve Otelcilik İşletmeciliği Yüksekokulu

TOYO = Turizm ve Otelcilik Yüksekokulu

UBF $=$ Uygulamalı Bilimler Fakültesi

$\mathrm{UBYO}=$ Uygulamalı Bilimler Yüksekokulu

\section{KAYNAKÇA}

Kozak, N., Tütüncü, Ö. ve Kozak, M. (2014). Rekreasyon ve Rekreasyon Yönetimi Programlarının Amaçları Ne Olmalı?. 6. Akademik Turizm Eğitimi Arama Konferansı Sonuç Raporu, 17-20 Nisan 2014, Muğla: Bodrum.

ÖSYM (2021). Yükseköğretim Kurumları Sinavı, https:// www.osym.gov.tr/TR,20842/2021.html, Erişim tarihi: 15.09.2021.

Tütüncü, Ö. (2008). Rekreasyon Yönetimi’ne Yönelik Üniversite Düzeyinde Bir Müfredat Geliştirme Önerisi, Anatolia: Turizm Araştırmaları Dergisi, 19 (1): 93-103.

Tütüncü, Ö. (2012). Rekreasyona Yönelik Disiplinlerarası Bir Doktora Programı Önerisi. I. Rekreasyon Araştırmaları Kongresi, 45-760. 12-15 Nisan 2012. Antalya: Kemer.

Tütüncü, Ö. Akgündüz, Y. ve Yeşilyurt, C. (2019). Rekreasyon Yönetimi ve Turizm İşletmeciliği Bölüm Müfredatlarının Karşılaştırılması, Anatolia: Turizm Araştırmaları Dergisi, Prof. Dr. Hasan Olalı Turizm Sempozyumu Özel Sayısı, 112-124.

Tütüncü, Ö. (2018). Fakülteleşme ve Rekreasyon Bölümleri, Anatolia: Turizm Araştırmaları Dergisi, 29 (2): 265-271.

Özkan TüTüNCÜ, Prof. Dr., Dokuz Eylül Üniversitesi, Necat Hepkon Spor Bilimleri Fakültesi, Rekreasyon Bölümü, 35330, Seferihisar, Izmir.

E-posta: ozkan.tutuncu@deu.edu.tr

ORCID: 0000-0002-2482-0893 